\title{
BJO Treatment for retinopathy of prematurity in infants born before 27 weeks of gestation in Sweden
}

Dordi Austeng, Karin B M Källen, Uwe W Ewald, et al.

Br J Ophthalmol published online November 30, 2009

doi: 10.1136/bjo.2009.170704

Updated information and services can be found at:

http://bjo.bmj.com/content/early/2009/11/30/bjo.2009.170704

These include:

$\mathbf{P}<\mathbf{P} \quad$ Published online November 30, 2009 in advance of the print journal.

Email alerting Receive free email alerts when new articles cite this article. Sign up in the box at service the top right corner of the online article.

Notes

Advance online articles have been peer reviewed and accepted for publication but have not yet appeared in the paper journal (edited, typeset versions may be posted when available prior to final publication). Advance online articles are citable and establish publication priority; they are indexed by PubMed from initial publication. Citations to Advance online articles must include the digital object identifier (DOIs) and date of initial publication.

To order reprints of this article go to:

http://bjo.bmj.com/cgi/reprintform

To subscribe to British Journal of Ophthalmology go to:

http://bjo.bmj.com/subscriptions 
Treatment for retinopathy of prematurity in infants born before 27 weeks of gestation in Sweden.

Dordi Austeng, MD ${ }^{1,5}$, Karin B.M. Källen, $\mathrm{PhD}^{3}$, Uwe W. Ewald, MD, $\mathrm{PhD}^{2}$, Agneta Wallin, $\mathrm{MD}^{4}$, Gerd E. Holmström, MD, $\mathrm{PhD}^{1}$

Departments of Ophthalmology ${ }^{1}$ and Women's and Children's Health ${ }^{2}$, University Hospital, Uppsala, Sweden Tornbladsinstitutet, University of Lund, Sweden ${ }^{3}$

St. Erik's Eye Hospital, Sweden ${ }^{4}$

Department of Ophthalmology, Trondheim University Hospital, Norway ${ }^{5}$

Corresponding author:

Gerd E Holmström, MD, PhD

Dept. of Ophthalmology

University Hospital

75185 Uppsala

Sweden

gerd.holmstrom@neuro.uu.se

Keywords: Retinopathy of prematurity, treatment, laser, population-based

\begin{abstract}
Aims To study various aspects of treatment for retinopathy of prematurity (ROP) in a Swedish population of extremely preterm infants born before 27 weeks of gestation.

Methods A national, prospective and population-based study was performed in Sweden from April 1, 2004 to March 31, 2007. The criteria for treatment of ROP accorded with the recommendations of the Early Treatment for Retinopathy of Prematurity Cooperative Group.
\end{abstract}

Results Twenty percent of the infants (99/506) were treated for ROP. The likelihood of reaching treatment criteria nearly doubled for each week of reduction in gestational age (GA) at birth. The first treatment was performed at an earlier postmenstrual age in the most immature infants. One third of the infants had more than one session of laser treatment.

Conclusions A high percentage of these extremely preterm infants required treatment for ROP. The likelihood of reaching treatment criteria increased with a decline in GA at birth. Although only a few infants progressed to ROP Stages 4 and 5, our findings indicate a potential for improvement of the treatment routines, both regarding timing and number of laser spots at the first treatment. 


\section{Introduction}

With improvements in neonatal care more extremely immature infants are surviving and complications like retinopathy of prematurity (ROP) have become an important problem. In most cases treatment is successful, if performed at an optimal time. Criteria for treatment were first presented in the CRYO-ROP study. ${ }^{1}$ Recently, new recommendations including earlier treatment were proposed in the Early Treatment for Retinopathy of Prematurity (ETROP) study. ${ }^{2}$ The present Swedish national study of extremely preterm infants shows a high incidence of ROP, ${ }^{3}$ in our population with high survival of these infants. ${ }^{4}$ The aim of the present study was to determine whether this population of extremely preterm infants differs from more mature ones as regards various aspects of treatment for ROP.

\section{Material and Methods}

This is a Swedish national project (The EXPRESS Study - Extremely Preterm Infants in Sweden) on the mortality and morbidity of extremely preterm infants born before 27 weeks of gestation. ${ }^{4}$ They were born in Sweden during a three year period, from April 1, 2004 to March 31, 2007. Data on screening and treatment for ROP for every infant <27 weeks GA born during the study period and surviving at least to the first eye examination, were continuously collected by a group of ophthalmologists. We used the International Classification of ROP revisited. ${ }^{5}$ Details on screening and incidence of ROP are given in a recent paper. ${ }^{3}$ The recommendations for early treatment for ROP (ETROP) were followed, ${ }^{2}$ which entail treating all infants with type 1 ROP, i.e. any stage ROP with plus disease in zone I, ROP 3 without plus disease in zone I, and ROP stage 2 or 3 with plus disease in zone II. As suggested by ETROP, infants with type 2 ROP i.e., stage 1 or 2 ROP without plus disease in zone I and ROP 3 without plus disease in zone II, were followed more careful. The infants were treated in one of the seven University Hospitals in Sweden as soon as possible and at least within 72 hours of the decision to treat. ${ }^{1}$

Laser photocoagulation was performed with the patient under general anaesthesia, using a laser indirect ophthalmoscope with double-frequency Nd:YAG laser. The eyes were treated with laser spots spaced no more than one spot size apart in avascular retina anterior to the ridge. ${ }^{6}$ Supplemental laser spots were applied to untreated areas if plus disease or fibrovascular proliferations were still present two weeks after the primary treatment. Cryotherapy, cerclage and vitrectomy were used when found indicated by the surgeon. Each infant was classified according to the maximum stage of ROP in either eye. ROP stages 1 and 2 were defined as mild and stages 3 to 5 as severe ROP.

Statistical analyses were performed using a commercially available software program (Gauss, Aptech Systems Inc., Maple Valley, Washington). Odds ratios (ORs) with 95\% confidence intervals $(\mathrm{CI})$ were calculated using multiple logistic regression analyses. The GA was analyzed using class variables or, if specified, was entered in the models as a linear continuous variable. If specified, adjustments were made for birth weight (BW) (continuous variable). The relation between number of laser spots and post menstrual age (PMA) and GA at birth, respectively, was studied using a simple linear regression analysis.

\section{Results}

The total cohort screened for ROP comprised 506 infants. ${ }^{3}$ Of these $37.9 \%(192 / 506)$ had mild (stages 1 and 2) and $34.8 \%$ (176/506) severe ROP (stages 3 to 5) and 19.6\% (99/506) of them were treated.

Of the 99 treated infants, 55 (55.6\%) were boys, 44 (44.4\%) girls, $84(84.8 \%)$ single births and $15(15.2 \%)$ multiple births. The mean and median GA and weights at birth of treated and 
untreated infants are shown in Table 1 . The GA and BW were significantly lower in infants treated for ROP than in those not treated $(\mathrm{p}<0.001)$.

Table 1 Gestational ages and birth weights of treated and untreated infants

\begin{tabular}{|l|l|l|l|l|l|l|}
\hline & \multicolumn{3}{|l|}{ Gestational age (weeks) } & \multicolumn{3}{l|}{ Birth weight (grams) } \\
\hline & Mean & Median & Range & Mean & Median & Range \\
\hline Treated $(\mathrm{n}=99)$ & 24.6 & 24.4 & $22.1-26.9$ & 673 & 660 & $361-1014$ \\
\hline Untreated $(\mathrm{n}=407)$ & 25.6 & 25.7 & $22.9-26.9$ & 802 & 791 & $348-1315$ \\
\hline
\end{tabular}

The percentages of infants treated in relation to their GA at birth are given in Table 2.

Table 2 Relation between number of infants treated for ROP and gestational age at birth.

\begin{tabular}{|l|l|l|l|l|l|l|}
\hline Gestational age at birth (weeks) & 22 & 23 & 24 & 25 & 26 & Total \\
\hline Number (\%) of infants treated & $4(80)$ & $23(43)$ & $31(31)$ & $28(16)$ & $13(7)$ & $99(20)$ \\
\hline Number (\%) of infants not treated & $1(20)$ & $30(57)$ & $68(69)$ & $143(84)$ & $165(93)$ & $407(80)$ \\
\hline Total & $5(100)$ & $53(100)$ & $99(100)$ & $171(100)$ & $178(100)$ & $506(100)$ \\
\hline
\end{tabular}

Multiple logistic regression analyses showed a significant relation between treatment and GA at birth $(\mathrm{p}<0.001)$. The risk of reaching the criteria for treatment was reduced by $56 \%$ for each week of increase in GA at birth (OR 0.44, CI 0.35-0.55). Adjustment for birth weight only slightly affected this relation (OR 0.58 , CI $0.44-0.76, \mathrm{p}<0.001)$.

Of the 176 infants with severe ROP, 99 (56\%) were treated. The risk of progression from ROP 3 to treatment criteria declined with increase in GA at birth $(\mathrm{p}<0.001)$. Logistic regression analyses showed that the Odds Ratios for requiring treatment for ROP 3 were nearly halved for each week of increase in gestational age at birth (OR 0.58, CI 0.43-0.79).

The first treatment was given at mean PMA of 37.6 weeks (range 32.1 - 46.9 weeks) and a median PMA of 36.4 weeks (5 and 95 percentiles, 32.9 respectively 42.9 weeks). Three infants were treated at PMA between 49 and 54 weeks because of local vessel anomalies in eyes with regressed ROP. PMA (mean and median) at first treatment was significantly lower in infants of lower gestational ages $(\mathrm{p}<0.05)$.

The various types of treatments are listed in Table 3. Both eyes were treated in 91 infants, while three were treated in the right eye and five in only the left eye. One third of the infants (30\% of the right and $28 \%$ of the left eyes) needed supplemental laser treatment. In $80 \%$ (79/99) of the infants, the first treatment was done within 72 hours, as recommended. Ten infants were treated 5 to 14 days after decision of treatment. All except one had plus disease in both eyes. Six of the ten infants needed more than one treatment and two of them progressed to ROP stage 4B and 5. All together, 19 doctors had treated the infants. The number of treatments per doctor ranged from one to 32; five of them had performed more than ten treatments and five less than three treatments. 
Table 3. Types of treatment given to the right and left eyes

\begin{tabular}{|l|l|l|}
\hline & Right eyes & Left eyes \\
\hline Laser & 85 & 86 \\
\hline Cryo & 1 & 2 \\
\hline Laser + cryo & 3 & 4 \\
\hline Laser + cerclage & 1 & 1 \\
\hline Laser + vitrectomy & 2 & 1 \\
\hline Laser + cryo + vitrectomy & 2 & 0 \\
\hline Laser + cryo + cerclage + vitrectomy & 0 & 2 \\
\hline Total & 94 & 96 \\
\hline
\end{tabular}

The numbers of laser spots were available in 79 right and 77 left eyes. The mean and median numbers of laser spots at the first treatment were 1069 and 1000 in the right and 1051 and 960 in the left eyes. The mean and median cumulative numbers of spots in the right eyes were 1337 and 1113 (range $380-3159$ ) and in the left eyes 1313 and 1150 (range 200 - 3157), respectively. Linear regression analyses showed a significant relation between the cumulative numbers of spots and the GA at birth in both eyes $(\mathrm{p}<0.05)$. These analyses also demonstrated a significant relation between the cumulative numbers of laser spots and PMA at the first treatment in both eyes $(\mathrm{p}<0.05)$ (Fig. 1). Three infants (three eyes) with opacities in the media were given cryotherapy alone.

Information of plus disease was recorded in all treated infants except two. Ninety three percent of the treated infants (90/97) had plus disease in at least one eye. Nine had Zone I disease. All the others, except one, had ROP in zone II. The latter infant developed ROP Stage 4A in zone III in one eye. He was treated with laser and the retina reattached. Aggressive posterior ROP (AP-ROP) was noted in four infants. Zone I was involved in all of them. In one infant with AP-ROP, the disease regressed after one session of laser. In the other three infants, ROP progressed and supplemental treatment with vitrectomy and/or cerclage was given.

\section{Discussion}

The present national study gives us new insight in three major aspects regarding treatment for ROP in extremely preterm infants. Firstly, the number of infants treated was high, $20 \%$, in this strictly population-based study with a high survival of extremely preterm infants born before 27 weeks of gestation. During the past decade several authors have reported an increase in the frequency of extremely preterm infants treated for ROP. ${ }^{78}$ For example, a Danish retrospective population-based study during the period 2001-2005 noted that $21 \%$ of infants with a gestation of less than 26 weeks required treatment. ${ }^{8}$ Analyses of a subgroup of infants with a GA<26 weeks in our study, however, shows an even higher frequency of $26 \%$ treated for ROP (Table 4). A Belgian retrospective study, which was done in 1999-2000, found threshold retinopathy in $19.8 \%$ of the surviving infants with a gestation of less than 27 weeks at birth. ${ }^{9}$ In that study $25 \%$ of the infants were born outside the hospital, and they were not included. Recent national population-based studies in the UK/Ireland and Norway have also reported a lower frequency of infants treated for ROP than here (Tale 4). ${ }^{11} \mathrm{In}$ agreement with Vyas at al, who related differences in incidence of severe ROP to variations in survival rates, we believe that the higher frequency of treatment that we found is due to the higher percentage of infants born in the earliest weeks of gestation. ${ }^{412}$ In the subgroup of infants with a gestation of less than 26 weeks at birth, the percentage of infants with a GA of 22 and 23 weeks is $18 \%$ in the present study versus $1-9 \%$ in the above mentioned studies. ${ }^{9-11}$ 
Table 4 Comparison of national population-based studies of infants with low gestational age (GA) performed in the last decade.

\begin{tabular}{|c|c|c|c|c|c|}
\hline Studies & Belgium $^{9}$ & Norway $^{11}$ & Denmark $^{8}$ & UK / Ireland ${ }^{10}$ & Present study \\
\hline Including infants with GA (weeks) & $<27$ & $<28$ & $<26$ & $<26$ & $<27$ \\
\hline Study period & $1999-2000$ & $1999-2000$ & $2001-2005$ & 1995 & 2004-2007 \\
\hline Number of infants with GA $<26$ & 70 & 99 & 196 & 309 & 328 \\
\hline Number of infants with GA $<27$ & 175 & 180 & & & 506 \\
\hline Number of infants with GA 22-23 & 1 & 9 & NA & 27 & 58 \\
\hline 24 & 19 & 35 & NA & 100 & 99 \\
\hline 25 & 50 & 55 & NA & 182 & 171 \\
\hline 26 & 105 & 81 & & & 178 \\
\hline Treated - percentage with GA $<26$ & & $14 \%$ & $21 \%$ & $15 \%$ & $26 \%$ \\
\hline percentage with GA $<27$ & $20 \%$ & $8 \%$ & & & $20 \%$ \\
\hline
\end{tabular}

NA, not available

Secondly, the present study shows that infants run a higher risk of reaching criteria for treatment with a lower GA at birth. In a prospective population-based study from Australia, Todd et al ${ }^{7}$ observed that of infants $<27$ weeks gestation who develop severe ROP, more than $60 \%$ were treated with laser. Our data support these findings - i.e., $56 \%$ of infants with severe ROP were treated. We also noted that the risk of reaching criteria for treatment was nearly halved for each week of increase in the GA at birth between 22 and 26 completed weeks. This reduction in risk also applied to progression from ROP 3 to the need for treatment. In the CRYO-ROP study, Schaffer et al found that infants ran a lower risk of reaching threshold with an increase in the gestational ages at birth. ${ }^{13}$ They reported that for each additional week of GA at birth, the odds ratios of reaching threshold were reduced by $19 \%$ and once ROP had occurred, the odds ratios were reduced by $14 \%$. The difference between the CRYO-ROP study and the present one may be due partly to differences in the study designs, the latter being a population-based and the former a multicenter one. Moreover, today, treatment is started earlier, as recommended in the ETROP study. ${ }^{2}$ The CRYO-ROP study was done 20 years ago and the neonatal care and population of infants who develop severe ROP in high income countries have changed a lot since then.

The third major insight from our study concerns timing of the first treatment of the extremely preterm infants. In addition to the increased risk of reaching treatment criteria, we found that the most immature infants reached these criteria earlier than the more mature ones. This accords with the findings of Coats et al, ${ }^{14}$ and points out the importance of efficient screening strategies to detect treatment-requiring ROP in due time in these extremely immature infants.

Although not affecting the major conclusions of the present study, there are some shortcomings which ought to be considered to promote future improvements of treatment routines in our country. ROP progressed to Stage 4 or 5 in only 6\% (5/99) of infants treated with laser and/or cryo, which suggests that ablative treatment, is effective. However, one third of the infants needed supplemental laser treatment. This frequency is similar to that reported in an Australian study, ${ }^{15}$ but higher than that in other studies (14-16\%). ${ }^{216} 17$ The mean cumulative number of laser spots (1337 in right and 1313 in left eyes) in our study was lower than in the ETROP study, which reported 1596 spots, ${ }^{2}$ and in a recent one by Axer-Siegel et al with 1740 spots. ${ }^{17}$ The low number of laser spots at the first treatment (1069 in right eyes and 1051 in left eyes) may explain our higher frequency of treatment sessions and emphasizes the necessity to look for skip areas before completion of the laser treatment. It seems likely that reducing the number of skip areas by an increase in the number of laser spots at the first treatment would reduce the progression of the disease as well as the frequency of treatment 
sessions. Moreover, in the present study, the frequency of zone I disease is lower than in the hospital-based studies of ETROP and Axer-Siegel et al (9\% versus 22-29\%, respectively), which would also contribute to the lower number of laser spots in our study.

In accordance with Axer-Siegel et al ${ }^{17}$ we found a significant correlation between the cumulative number of laser spots and the GA at birth. We also found a significant association between the cumulative number of laser spots and the PMA at treatment, which is not unexpected since infants treated at lower PMAs have more extended avascular areas and need a larger number of laser spots for ablation. Therefore, as regards the number of laser spots, both the GA at birth, ${ }^{17}$ and the PMA should be taken into account at the time of the first treatment.

The criteria for treatment, according to the ETROP recommendations, ${ }^{2}$ were fulfilled in at least one eye in $93 \%$ of the infants in the present cohort. Nine infants were treated in both eyes although they had plus disease in only one. Seven infants had no plus disease and were treated for various health or practical reasons - i.e., to stop rapid progression of the disease, to avert the use of additional sedation and/or to prevent the transportation of the infants between hospitals. Therefore clinical judgement was used in the individual cases, which accords with the ETROP recommendations. ${ }^{2}$

Other problems of treatment routines in our country could also be identified. Regarding time between decision to treat and the first treatment, 20\% (20/99) of the infants were treated after the 72 hours stipulated in the study protocol. Further, many doctors were involved in the treatments and several of them treated only a few infants. In addition to the suggested increase in the number of laser spots at the first treatment, these findings are a potential for further improvement of routines of treatment for ROP in these infants.

Laser treatment has been the method of choice since the early 1990s. ${ }^{18-21}$ This is apparent in the present study, in which almost all (97\%) of the infants were treated with laser. In certain cases, however, cryotherapy still has a role to play. The small number of vitrectomies and cerclage prevents us from drawing any conclusions about these procedures. All nine eyes, however, had an unfavourable anatomical and functional outcome (best corrected visual acuity $\leq 0.1)$. These numbers resemble those of studies from Denmark ${ }^{8}$ and the $\mathrm{UK}^{16}$ on early detection of visual impairment attributed to ROP.

In conclusion, this national population-based study of infants born before 27 gestational weeks shows that the most immature infants have a higher risk of reaching treatment criteria for ROP, a higher risk of progression from ROP 3 to treatment criteria and, finally, they reach these criteria at an earlier PMA than less immature preterms. Therefore, adequate screening and treatment for ROP, including timing as well as number of applied laser spots, are particularly important in the most immature infants.

Acknowledgement: The EXPRESS Group: M. Blennow, U. Ewald, V. Fellman, T. Fritz, L. Hellström-Westas, P-Å. Holmgren, G. Holmström, A. Jeppsson, K. Källén, H. Lagercrantz, R. Laurini, E. Lindberg, A. Lundqvist, K. Maršál (principal investigator), T. Nilstun, S. Nordén Lindeberg, M. Norman, E. Olhager, P. Otterblad Olausson, I. Östlund, F. Serenius, M. Simic, G. Sjörs, L. Stigson, K. Stjernqvist, B. Strömberg, M. Wennergren, and M. Westgren. Regional Ophthalmological Coordinators: A. Hellström, G. Holmström, P. Jakobsson, K. Johansson, K. Tornqvist, and A. Wallin. 
Ophthalmologic co-investigators: S. Andersson, S. Andreasson, B. Arif, I. Axelsson, L. Berglin, I. Berndtson, E. Bonthron, B. Carlsson, P. Carlström, G. Cernerud, M. Cheraghchi, A. Collath, S. Crafoord, K. Dimitriou, A. Felix, Y. Friberg Riad, Å. Fridman, K. Fromm, L. Gustad, N. Hagwall, M. Hammarbäck, L. J. Hansson, K. Hellgren, L. Hilmertz, K. Holm, M. Hök Wikstrand, E. Hörnblad, A-L. Hård, G. Ilic Sundström, N. Jadidi, G. Jakobsson, S. Jarkman, K. Johansson, P. Karlsson, L. Kjellberg, D. Kjellgren, T. Krebser, M. Kuusik, A. Kvanta, E. Larsson, U. Liden, C. Liljedahl, G. Lindgren, G. Lindgärde, C. Lundberg, I. Lundqvist, O. Lundqvist, Ö. Lundström, T. Lunt, E. Maly, T. Marczuk, Å. Nilsson, B. Nordin, G. Olivestedt, G. Olsson-Lalor, W. Owczarska, G. Pehrsson-Palmqvist, J. Rudebjer, A. Sellman, L. Sjödell, B. Sjödin-Backlund, B. Steen, E. Streman, B. Sunnqvist, S. Svedenhag, I. Taylor, O. Textorius, K. Teär-Fahnehjelm, I. Theocharis, Z. Tomic, O. Wennhall, A. Wieslander, A. Wrigstad, A. Östberg, H. Åkerblom, G. Åkerskog, and S. Åström.

Funding: This study was supported by the Birgit and Sven Håkan Olsson Foundation, the Evy and Gunnar Sandberg Foundation, Kronprinsessan Margarethas Arbetsnämnd för synskadade and the Swedish Association of the Visually Impaired.

Competing interests: None Declared

Ethics approval: The study was approved by the Ethics Committee, Faculty of Medicine, Lund University, Sweden.

Licence statement: The Corresponding Author has the right to grant on behalf of all authors and does grant on behalf of all authors, an exclusive licence (or non-exclusive for government employees) on a worldwide basis to the BMJ Publishing Group Ltd and its Licensees to permit this article (if accepted) to be published in British Journal of Ophthalmology and any other BMJPGL products to exploit all subsidiary rights, as set out in our licence

\section{Figure legend:}

Figure 1. Linear regression analyses of postmenstrual age at treatment and cumulative numbers of laser spots in both eyes.

\section{References:}

1 Cryotherapy for Retinopathy of Prematurity Cooperative G. Multicenter trial of cryotherapy for retinopathy of prematurity. Preliminary results. Arch Ophthalmol 1988;106:471-9.

2 Early Treatment For Retinopathy Of Prematurity Cooperative G. Revised indications for the treatment of retinopathy of prematurity: results of the early treatment for retinopathy of prematurity randomized trial. Arch Ophthalmol 2003;121:1684-94.

3 Austeng D, Källen KBM, Ewald UW et al. Incidence of Retinopathy of Prematurity in Infants Born before 27 Weeks of Gestation in Sweden. Arch Ophthalmol 2009; 127:1315-19.

4 The EXPRESS Group. One-Year Survival of Extremely Preterm Infants After Active Perinatal Care in Sweden. JAMA 2009;301:2225-33.

5 International Committee for the Classification of Retinopathy of Prematurity. The International Classification of Retinopathy of Prematurity revisited. Arch Ophthalmol 2005;123:991-9.

6 Hardy RJ, Good WV, Dobson V et al. Multicenter trial of early treatment for retinopathy of prematurity: study design. Control Clin Trials 2004;25:311-25.

7 Todd DA, Wright A, Smith J et al. Severe retinopathy of prematurity in infants $<30$ weeks' gestation in New South Wales and the Australian Capital Territory from 1992 to 2002. Arch Dis Child Fetal Neonatal Ed 2007;92:F251-54. 
Slidsborg C, Olesen HB, Jensen PK et al. Treatment for retinopathy of prematurity in Denmark in a ten-year period (1996 2005): is the incidence increasing? Pediatrics 2008;121:97-105.

9 Vanhaesebrouck P, Allegaert K, Bottu J et al. The EPIBEL Study: Outcomes to Discharge From Hospital for Extremely Preterm Infants in Belgium. Pediatrics 2004;114:663-75.

10 Costeloe K, Hennessy E, Gibson AT et al. The EPICure study: outcomes to discharge from hospital for infants born at the threshold of viability. Pediatrics 2000;106:65971.

11 Markestad T, Kaaresen PI, Ronnestad A et al. Early Death, Morbidity, and Need of Treatment Among Extremely Premature Infants. Pediatrics 2005;115:1289-98.

12 Vyas J, Field D, Draper ES et al. Severe retinopathy of prematurity and its association with different rates of survival in infants of less than $1251 \mathrm{~g}$ birth weight. Arch Dis Child Fetal Neonatal Ed 2000;82:F145-9.

13 Schaffer DB, Palmer EA, Plotsky DF et al. Prognostic factors in the natural course of retinopathy of prematurity. The Cryotherapy for Retinopathy of Prematurity Cooperative Group. Ophthalmology 1993;100:230-7.

14 Coats DK, Paysse EA, Steinkuller PG. Threshold retinopathy of prematurity in neonates less than 25 weeks' estimated gestational age. J AAPOS 2000;4:183-85.

15 Lee GA, Hilford DJ, Gole GA. Diode laser treatment of pre-threshold and threshold retinopathy of prematurity. Clin Exp Ophthalmol 2004;32:164-9.

16 Haines $\mathbf{L}$, Fielder AR, Baker $\mathrm{H}$ et al. UK population based study of severe retinopathy of prematurity: screening, treatment, and outcome. Arch Dis Child Fetal Neonatal Ed 2005;90:F240-4.

17 Axer-Siegel R, Maharshak I, Snir M et al. Diode laser treatment of retinopathy of prematurity: anatomical and refractive outcomes. Retina 2008;28:839-46.

18 Iverson DA, Trese MT, Orgel IK et al. Laser photocoagulation for threshold retinopathy of prematurity. Arch Ophthalmol 1991;109:1342-3.

19 McNamara JA, Tasman W, Brown GC et al. Laser photocoagulation for stage 3+ retinopathy of prematurity. Ophthalmology 1991;98:576-80.

20 McNamara JA, Tasman W, Vander JF et al. Diode laser photocoagulation for retinopathy of prematurity. Preliminary results. Arch Ophthalmol 1992;110:1714-6.

21 Hunter DG, Repka MX. Diode laser photocoagulation for threshold retinopathy of prematurity. A randomized study. Ophthalmology 1993;100:238-44. 

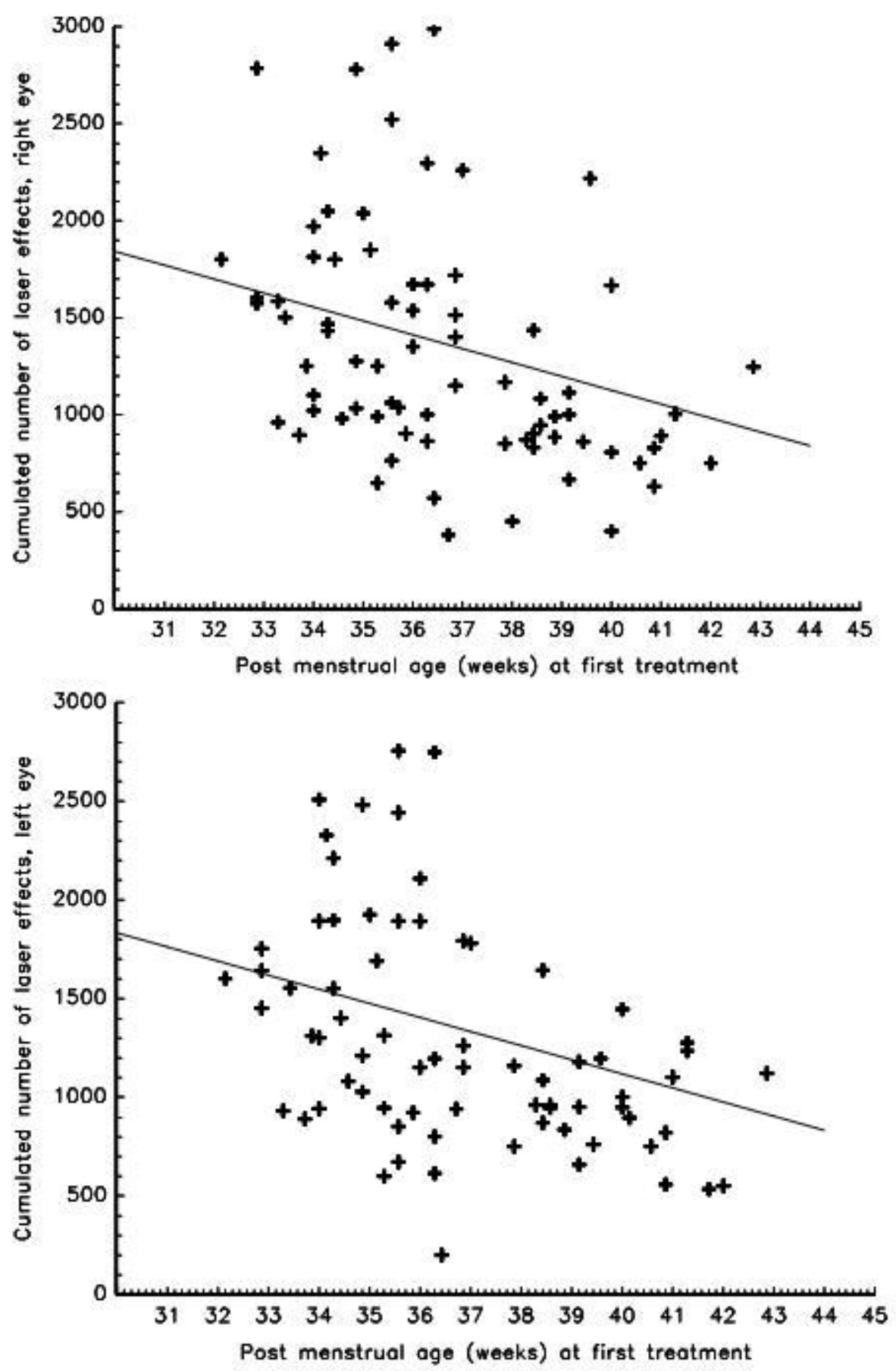